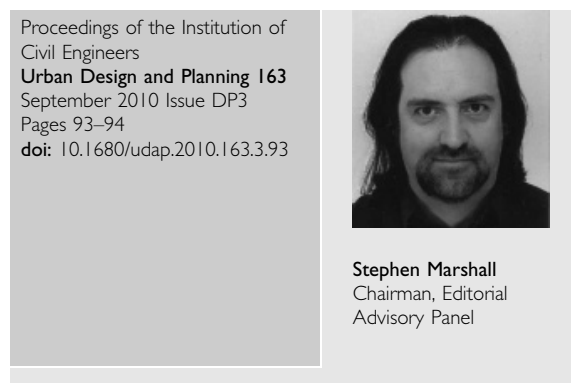

\title{
Editorial: Sustainability in transition
}

S. Marshall BEng, DipUD, MSc(Eng), PhD, MCIT, MIHT

Sustainability has become a dominant concern of our age, despite a lack of agreement on exactly what it is or how to achieve it. This sets the concept of sustainability apart from, for example, the internet age or globalisation, whose meaning and achievability are clear enough, not least because they refer to phenomena already in existence. In contrast, sustainability often seems to be grounded in the future. So we should not be surprised to find that sustainability is hard to pin down in advance, and indeed, changing in front of us.

As a general concept, sustainability often seems elusive, meaning different things at different times to different people. In a sense, sustainability is in the eye of the beholder.

Sustainability may be advocated as if propagating things into the future were intrinsically virtuous. Sometimes, the term 'sustainable' is used as if simply a badge of good intentions, or a promotional label for a package of best practice.

As a property, sustainability eludes capture by a single definitive unit of measurement. Of course, there is a smorgasbord of sustainability indicators to choose from, but there seems to be no single measure we can point to that can definitively track the trajectory of sustainability, as we can with population or GDP. Additionally it is not necessarily clear whether the property of sustainability resides in particular things and activities - a 'sustainable' building here or a 'sustainable' activity there - or if it may only be interpreted with respect to the wider ecosystem or a whole planet.

As a goal, sustainability is also elusive. It can sometimes seem unachievable, not least where current behaviour seems to be pointing irredeemably in the wrong direction. Or, while we might make one particular thing sustainable, it is not clear that we could ever make all things sustainable, simultaneously. Sustainability can seem difficult to achieve because the future is unpredictable, and the needs of future generations unknowable. In any case, it is not always clear if sustainability is simply an abstract ideal, a general direction of travel, or if it could be an actual achievable state.

As an actual achievable state, we must be careful about what we wish for, in case the only truly sustainable state were that of subsistence living. Eking out a frugal existence in small populations of hunter-gatherers spread over empty continents may have been demonstrably sustainable for millennia, but is not a prospect that most people would wish for themselves, to be sustained indefinitely into the future.

Alternatively, we could simply regard sustainability as a way of looking at the world: a perspective or paradigm in which we consider the three dimensions of society, economy and environment together, extending over the fourth dimension of time. In this case, sustainability is no longer an elusive property or an unattainable goal, but signifies a definite attitude: something we can adopt every time we design, plan or assess anything.

With this attitude, we need not allow problems with the elusive concept of sustainability to stop us attending to the very real properties or goals lying behind it - such as quality of life, social equity, economic vitality and environmental sustenance. The unknowable nature of the future need not deter us from thinking through the long-term consequences of our current behaviour. We need not allow the apparent intractability of the planet's problems to discourage us from making vital improvements that can be made, step by step; or allow scepticism about satisfying future generations to stop us addressing environmental justice for people here and now.

And so, while the meaning and value of the concept of sustainability may be uncertain, we can yet be specific about our aims, transparent in our judgements, and pragmatic in our actions. Rather than aspiring vaguely to a sustainable future, we can focus on tangible goals, such as minimising carbon, energy or climate change (duly measurable in tonnes, Joules, degrees or metres of sea level rise). Rather than hiding difficult decisions under a smokescreen of sustainability predicated on unknown hypothetical futures, we can make decisions on a transparent basis, using indicators that make sense of themselves, irrespective to how one might define 'sustainability'. And rather than being paralysed by indecision and inaction in the face of unknowable optimum 'sustainable' solutions for unborn generations, we can fix things that we know need fixing in the present: the buildings that burn up so much of our energy, or the vehicles that choke so many of our streets.

This issue of Urban Design and Planning contains a selection of papers that duly get to grips with various aspects of defining, assessing and achieving sustainability. We start with two briefings that represent two major investigations from the UK relating to sustainability. Rydin et al. (2010) report key findings 
from the UK Foresight programme, advocating the need for change in the built environment: change in energy systems, change in behaviour and change in government approaches. Meanwhile, Paranagamage et al. (2010) report on a major programme of research (SUE-MoT) investigating hundreds of methods, metrics or tools for assessing sustainability. Selected papers reporting different aspects of this research programme will feature in subsequent issues of this journal.

Subsequently, Mohareb (2010) sets out a way of addressing land use as a sustainability indicator in the context of Arab cities. Mohareb concludes that Arab cities should not merely replicate models from Western cities, but need approaches adapted to their specific conditions. In the next paper, Femenias and Fudge (2010) report on research into retrofitting non-domestic buildings in the UK, with particular attention to office developments in Bristol. This research highlights circumstances in which commercial and community interests are seen to be more influential than carbon reduction or energy efficiency. Finally, Perera et al. (2010) discuss the human exposure to street-level air pollution, addressing modelling of impacts and mitigation options. Here, it can be concluded that the planning and design of urban form can have a role in influencing air quality and human health - and hence ultimately (though the authors do not use the term) sustainability.

Taken together, the papers in this issue reflect the increasing focus on specific critical issues such as health, decarbonisation, energy reduction and climate change, rather than a preoccupation with sustainability in general. The research addresses a range of issues - the development of Arab cities, the adaptability of buildings, or the very air we breathe - that should be of interest or concern to urban designers and planners whether or not these topics are considered within the paradigm of sustainability.

It is also interesting to note that Rydin et al. (2010) consider four alternative scenarios for sustainability, rather than a single target state, while Mohareb (2010) interprets sustainable development as just one possible model in an unfolding series not necessarily the last or best model. Tellingly, the research by
Rydin et al. is explicitly informed by an understanding of the co-evolution of social and economic issues, governance and technology: the drivers of urbanism are interdependent and change in relation to each other. As with biological evolution, urban change is not linear or progressive and there is no knowable optimum future (Marshall, 2009).

This all suggests that the idea of sustainability is in transition; and there can be no single model for a desired future sustainable state. Rather, there is an ever-changing environment where the goal-posts are always moving. There is no fixed status quo to be 'sustained' into the future. 'What is to be sustained' will always be open to question and reinterpretation. What is deemed 'sustainable' today may not turn out to be 'sustainable' tomorrow.

\section{REFERENCES}

Femenias P and Fudge C (2010) Retrofitting the city: reuse of non-domestic buildings. Proceedings of the Institution of Civil Engineers, Urban Design and Planning 163(3): 117126, doi: 10.1680/udap.2010.163.3.117.

Marshall S (2009) Cities, Design and Evolution. Routledge, Abingdon and New York.

Mohareb NI (2010) Land use as a sustainability indicator for Arab cities. Proceedings of the Institution of Civil Engineers, Urban Design and Planning 163(3): 105-116, doi: 10.1680/ udap.2010.163.3.105.

Paranagamage P, Price A and Khandokar F (2010) Briefing: Holistic assessment of sustainable urban development. Proceedings of the Institution of Civil Engineers, Urban Design and Planning 163(3): 101-104, doi: 10.1680/ udap.2010.163.3.101.

Perera B, Emmanuel R and Nandasena S (2010) Urban air pollution and mitigation options in Sri Lanka. Proceedings of the Institution of Civil Engineers, Urban Design and Planning 163(3): 127-138, doi: 10.1680/udap.2010.163.3.127.

Rydin Y, Thomas S and Beddington J (2010) Briefing: Energy and the built environment. Proceedings of the Institution of Civil Engineers, Urban Design and Planning 163(3): 95-99, doi: 10.1680/udap.2010.163.3.95. 